\title{
Seven-year results with the St Jude Medical Silzone mechanical prosthesis
}

W. R. Eric Jamieson, MD, Guy J. Fradet, MD, James G. Abel, MD, Michael T. Janusz, MD, Samuel V. Lichtenstein, MD, PhD, Joan S. MacNab, Elizabeth A. Stanford, BScN, and Florence Chan

Objective: The Artificial Valve Endocarditis Reduction Trial was stopped on January 21, 2000, due to a higher incidence of paraprosthetic leak in the St Jude Medical Silzone prosthesis compared with the conventional prosthesis. The Artificial Valve Endocarditis Reduction Trial investigators reported the 2-year results in 2002. This retrospective study assessed the influence on thromboembolism and paraprosthetic leak to 7 years.

Methods: A total of 253 patients had 254 operations: 80 aortic valve replacements, 139 mitral valve replacements, and 35 multiple replacements with placement of Silzone prostheses. The mean age was 58.6 years (range 21-84 years, median age 59.8 years), and there were 126 women $(49.8 \%)$ and 74 concomitant procedures (coronary artery bypass $28.9 \%$ ).

Results: Major paraprosthetic leak (repair, re-replacement, or mortality) occurred in 10 of the original procedures after 30 days ( 3 aortic valve replacements, 3 mitral valve replacements, 4 multiple replacements). Nine occurrences in 8 patients -5 early ( $\leq 2$ years) and 4 late ( $>2$ years) — were managed. Seven were managed with definitive re-replacement. One was an early nonoperative fatality. There was 1 late fatality after the second late paraprosthetic leak reoperation. One of the 10 procedures occurring after 2 years had mild to moderate aortic valve replacement paraprosthetic leak managed as an incidental re-replacement at the time of correction of supra valvular patch stenosis. One additional occurrence, in addition to the 8 patients ( $<30$ days), was considered a technical error and not related to the Silzone prosthesis and was replaced with a Silzone prosthesis. The linearized rate of paraprosthetic leak within the first 2 years of follow-up was 1.3\%/patient-year and after 2 years was $0.4 \% /$ patient-year. The linearized occurrence rate for major thromboembolism was $0.42 \% /$ patient-year for aortic valve replacement and $1.71 \%$ /patient-year for mitral valve replacement.

Conclusions: Paraprosthetic leak with the St Jude Medical Silzone prosthesis was managed both during the early $(\leq 2$ years) and late ( $>2$ years) intervals with re-replacement. Late managed events may be manifestations of earlier occurring paraprosthetic leak. Follow-up echocardiograms should meet standards of care, 6 to 12 months after surgery and at the slightest suspicion of dysfunction. There is no advanced continuing risk of the St Jude Medical Silzone prosthesis.

Supplemental material is available online.

Prosthetic valve endocarditis is an infrequent but severe complication following heart valve replacement. St Jude Medical introduced Silzone, silver impregnated onto the sewing cuff of all valvular products as prophylaxis against early prosthetic valve endocarditis, in 1998. The Artificial Valve Endocarditis Reduction Trial (AVERT) was commenced in July of 1998 and was suspended on January 21,

\footnotetext{
From the University of British Columbia, Vancouver, Canada.

Presented to the World Society of Cardio-Thoracic Surgery, Ottawa, Canada, August 17 to $20,2006$.

Received for publication Dec 7, 2007; revisions received May 6, 2008; accepted for publication July 4, 2008.

Address for reprints: W. R. Eric Jamieson, MD, 486 Burrard Building, St Paul's Hospital, 1081 Burrard Street, Vancouver, BC, Canada V6Z 1Y6 (E-mail: eric. jamieson@ubc.ca).

J Thorac Cardiovasc Surg 2009;137:1109-15

0022-5223/\$36.00

Copyright (c) 2009 by The American Association for Thoracic Surgery

doi:10.1016/j.jtcvs.2008.07.070
}

2000, when the prospective randomized trial revealed a higher incidence of paraprosthetic leak (PPL) in the Silzone arm of the trial. The trial had placed implants in 807 of the anticipated 4400 patients. Worldwide, 36,000 implantations were performed before the study was suspended, and the valve was voluntarily removed from the market by $\mathrm{St}$ Jude Medical. This center, participating in AVERT, randomized 90 patients (44 Silzone). Our center placed $254 \mathrm{im}$ plants in 253 patients, inclusive of the 44 patients enrolled in AVERT. The purpose of the study was to assess the influence of the St Jude Medical Silzone on late thromboembolism and PPL and to provide surveillance recommendations.

The investigators of the AVERT trial in Europe and North America reported the results of this multicenter, international, prospective, randomized trial in 2002. ${ }^{1}$ Major PPL (followed by repair, explant, or mortality) occurred in 18 of 403 patients $(4.5 \%)$ with Silzone prostheses and 4 of 404 patients $(1.0 \%)$ with conventional prostheses. The 2 year event-free rates were $91.1 \%$ for Silzone versus $98.9 \%$ for conventional prostheses $(P=.0025)$. Similarly, the 2-year freedom from explant was $90.1 \%$ and $99.4 \%$, respectively, for Silzone and conventional prostheses 


\section{Abbreviations and Acronyms \\ AVERT $=$ Artificial Valve Endocarditis Reduction Trial \\ AVR $=$ aortic valve replacement \\ MR = multiple replacements \\ MVR = mitral valve replacement \\ OPC = Objective Performance Criteria \\ PPL = paraprosthetic leak}

$(P=.0002)$. The freedom from thromboembolism was not different: $91.2 \%$ for Silzone and $93.4 \%$ for conventional prostheses $(P=.32)$.

\section{MATERIAL AND METHODS Patients}

The St Jude Medical Silzone valvular prosthesis was implanted in 253 patients (254 procedures; mean patient age 58.6 years, range $21-84$ years, median 59.8 years) between 1998 and January 2000, when the prosthesis was voluntarily withdrawn from the worldwide market with suspension of the AVERT trial. There were 127 men $(50.2 \%)$ and 126 women $(49.8 \%)$ in the total cohort of 253 patients. There were 254 operations: 80 (31.5\%) aortic valve replacements (AVRs); 139 (54.7\%) mitral valve replacements (MVRs); and 35 (13.8\%) multiple replacements (MR). One patient having MVR also had a second Silzone prosthesis implanted at a second reoperation procedure for technical error and PPL. Concomitant procedures were performed in 102 patients $(40.2 \%)$, including 74 concomitant coronary artery bypass procedures $(28.9 \%)$.

The total cumulative follow-up was 1399.7 years with a mean follow-up of $5.5 \pm 2.3$ years (median 6.3 years). The follow-up had a closing interval of 2 months in November 2005.

\section{Study Definitions}

The study was conducted under the standard definitions of The Society of Thoracic Surgeons/American Association for Thoracic Surgery/European Association for Cardio-thoracic Surgery "Guidelines for Reporting Morbidity and Mortality after Cardiac Valvular Operations.,"2 Major PPL was defined (as in the AVERT publications) as a paravalvular leak that led to prosthesis repair, prosthesis explant, or mortality.

Thromboembolism events included major cerebrovascular accidents, transient ischemic attacks, reversible ischemic neurologic deficits, arterial embolization, and embolic myocardial infarction. Valve thrombosis was defined as thrombus attached to or near the study valve, occluding blood flow or interfering with function (proven by operation, autopsy, or clinical investigation), exclusive of infection. Hemorrhage was defined as bleeding resulting in blood transfusion and/or hospitalization.

\section{Statistical Methods}

The early and late complications were analyzed with conventional techniques. The 30-day event complications and mortality rates were presented as crude rates without time involved. Linearized rates (\%/patientyear) for events beyond 30 days were calculated by taking the total number of late events divided by the sum of the late follow-up years beyond 30 days. The Kaplan-Meier event-free analysis method was used to calculate freedom from various valve-related complications. The Kaplan-Meier analysis included both early and late events but only the first of each type for each patient. Comparisons were performed with the log-rank test.

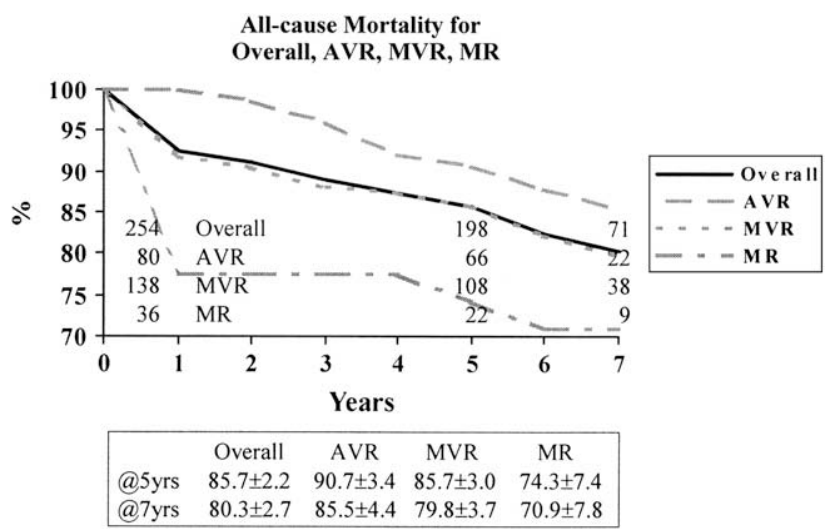

FIGURE 1. All-cause mortality overall and for aortic valve replacement $(A V R)$, mitral valve replacement $(M V R)$, and multiple replacements $(M R)$.

\section{RESULTS}

The actuarial analyses of the results for the overall population and the separate populations of AVR, MVR, and MR are presented in graphic form in Figures 1 and 2 and the supplemental electronic Figures E1 to E9, stated at the intervals of 5 and 7 years.

The overall patient survival depicting all-cause mortality is illustrated in Figure 1. The overall survival at 7 years was $80.3 \% \pm 2.7 \%$, for AVR $85.5 \% \pm 4.4 \%$, and for MVR $79.8 \% \pm 3.7 \%$.

The early and late predominant valve-related complications are detailed in Table 1 and are presented as crude 30day event rates and late linearized occurrence rates (plus $95 \%$ confidence intervals). There were 4 early major thromboembolic events: 1 AVR and 3 MVRs. There were 6 early hemorrhagic events: 2 AVRs, 2 MVRs, and 2 MR. There was 1 fatal MVR hemorrhagic event. There was 1 early MVR PPL, which resulted in 2 reoperations in less than 3 weeks and was classified as technical failure.

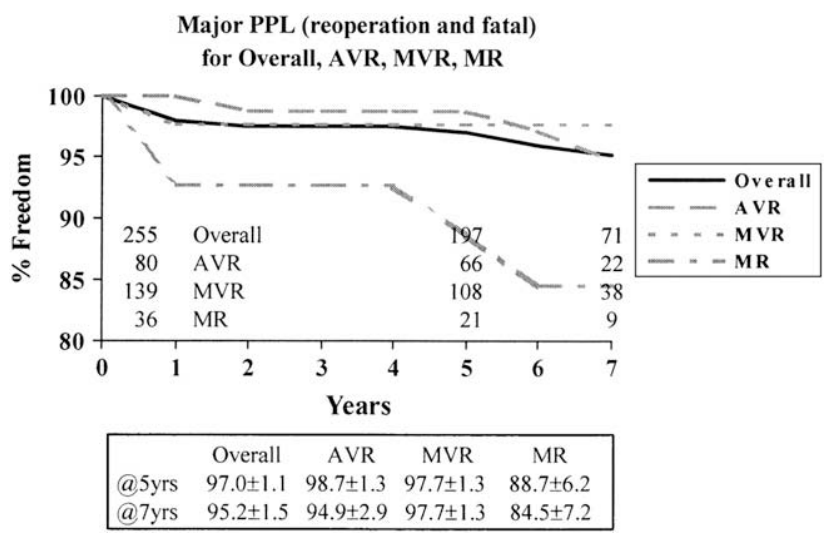

FIGURE 2. Major paraprosthetic leak (reoperation and fatal) overall and for aortic valve replacement $(A V R)$, mitral valve replacement $(M V R)$, and multiple replacements $(M R)$. 
TABLE 1. Early events and late linearized rates (\%/patient-year) for AVR, MVR, and MR complications

\begin{tabular}{|c|c|c|c|c|c|c|c|c|c|}
\hline & \multicolumn{3}{|c|}{ AVR } & \multicolumn{3}{|c|}{ MVR } & \multicolumn{3}{|c|}{ MR } \\
\hline & Early & Late & CI & Early & Late & CI & Early & Late & CI \\
\hline TE Major + RIND & 1 & $0.42(2)$ & $0.00-1.00$ & 3 & $1.71(13)$ & $0.79-2.64$ & 0 & $0(0)$ & - \\
\hline Hemorrhage & 2 & $1.67(8)$ & $0.52-2.82$ & $2^{*}$ & $1.98(15)$ & $0.99-2.97$ & 2 & $4.28(7 *)$ & $1.18-7.38$ \\
\hline Major PVL & 0 & $0.63(3 *)$ & $0.00-1.34$ & 1 & $0.40(3)$ & $0.00-0.84$ & 0 & $2.45(4 *)$ & $0.08-4.81$ \\
\hline VR REOP & 0 & $0.63(3 \dagger)$ & $0.00-1.34$ & 2 & $0.53(4 \ddagger)$ & $0.01-1.04$ & 0 & $3.06(5 \dagger)$ & $0.42-5.70$ \\
\hline PVE & 0 & $0.21(1)$ & $0.00-0.62$ & 2 & $0.00(0)$ & $0.00-0.00$ & 0 & $0.61(1)$ & $0.00-0.81$ \\
\hline Thrombosis & 0 & $0.00(0)$ & $0.00-0.00$ & 0 & $0.13(1)$ & $0.00-0.39$ & 0 & $0.00(0)$ & $0.00-0.00$ \\
\hline
\end{tabular}

$A V R$, Aortic valve replacement; $C I$, confidence interval; $M R$, multiple replacements; $M V R$, mitral valve replacement; $P V E$, prosthetic valve endocarditis; $P V L$, paravalvular leak; RIND, reversible ischemic neurologic deficits; TE, thromboembolism; VR REOP, valve-related reoperation. *Fatal (1). †PVE (1). †Thrombosis (1).

The late event rates for major thromboembolism for AVR were $0.42 \% /$ patient-year ( 2 events) and for MVR, $1.71 \%$ patient-year (13 events; Table 1$)$. There were no events in the multiple valve cohort. The hemorrhage rates ranged from 1.67\%/patient-year ( 8 events) for AVR to $1.98 \%$ / patient-year (15 events) for MVR and to $4.31 \%$ /patient-year (7 events) for MR. There was 1 late MR hemorrhagic fatality.

The major late PPL event rates were 0.63/patient-year (3 events) for AVR, 0.40\%/patient-year (3 events) for MVR, and 2.45\%/patient-year (4 events) for MR (Tables 1, 2, and 3). There was 1 AVR PPL fatality; this patient was definitively diagnosed 15 months postoperatively and died the same month under consideration for reoperation (Table 3). One patient with MR had a sixth valvular operation in 24 years; the fifth was a repair of PPL of an aortic Silzone prosthesis and the sixth was a further aortic valved conduit operation for an additional PPL at a remote surgical position. The patient subsequently died.

The late linearized rate for events within 2 years of surgery for major PPL was 1.3\%/patient-year, and the late event rate during the subsequent follow-up period was $0.4 \% /$ patient-year.

The reoperation rates were $0.63 \% /$ patient-year ( 3 events) for AVR, 0.53\%/patient-year (4 events) for MVR, and $3.06 \% /$ patient-year (5 events) for MR (Table 1 ). These reoperations were all for PPL except for an aortic and multiple prosthetic valve endocarditis and a thrombosed mitral prosthesis (Table 3 ).

The details of the PPL occurrences are summarized in Tables 2 and 3. Five of the 9 PPLs were diagnosed at $\leq 2$ years for surgical management. Of the 4 PPLs diagnosed at $>2$ years, 1 patient with AVR had re-replacement surgery at 6.3 years and 1 multiple replacement-AVR repair at 4.7 years, and subsequently was replaced with a mechanical valve conduit at 5.7 years and another MR-MVR with replacement surgery at 5.8 years with aortic valve and mitral valve bioprostheses. The additional AVR occurrence had incidental re-replacement for mild to moderate PPL at surgery for revision of an aortic annular enlarging patch causing supravalvular stenosis (Table 3). MR reoperation at 4.7

TABLE 2. Summary of location, timing, and details of reoperation for PPLs considered related to Silzone prosthesis (including 6 major and 1 mild to moderate leak)

\begin{tabular}{|c|c|c|}
\hline Location & Timing & Details \\
\hline AVR & $5.1 \mathrm{y}$ & $\begin{array}{l}\text { Mild to moderate PPL and supravalvular stenosis (serial mean gradients up to } 40 \mathrm{~mm} \mathrm{Hg} \text { ) from previous aortic } \\
\text { root annular enlarging patch. Re-replacement and patch revision. }\end{array}$ \\
\hline AVR & $6.3 \mathrm{y}$ & $\begin{array}{l}\text { Ascending aortic aneurysm resection prior to Silzone AVR. Congestive heart failure at } 5.7 \mathrm{y} \text {, PPL confirmed } \\
\text { and re-replacement at } 6.3 \mathrm{y} \text {. }\end{array}$ \\
\hline MVR & $5.5 \mathrm{mo}$ & Major PPL, not considered of infective etiology. Re-replacement. \\
\hline MVR & $5.3 \mathrm{mo}$ & $\begin{array}{l}\text { Reoperation for thrombosed conventional prosthesis with Silzone prosthesis followed at } 5 \text { mo for major PPL } \\
\text { with attempted repair/re-replacement. }\end{array}$ \\
\hline MR (AVR) & $4.7 \mathrm{y}$ & $\begin{array}{l}\text { Six valvular operations in } 24 \text { years. Initial Starr-Edwards AVR (Edwards Lifesciences, Irvine, Calif), Medtronic } \\
\text { Intact (Medtronic, Inc, Minneapolis, Minn) porcine for mechanical structural valve deterioration, further } \\
\text { Medtronic Intact porcine for prosthetic valve endocarditis. Nine years later, AVR and MVR Silzone for } \\
\text { suspected endocarditis. At } 4.7 \text { y, moderate PPL, noncoronary leaflet PPL repaired. One year later, composite } \\
\text { mechanical root replacement for major PPL at different annular site, just left of the native right coronary } \\
\text { ostia; patient subsequently died in hospital. }\end{array}$ \\
\hline MR (MVR) & $7.5 \mathrm{mo}$ & $\begin{array}{l}\text { Initially AVR and MVR CarboMedics mechanical prostheses (Sorin-CarboMedics, Austin, Tex); at } 4.3 \text { y MVR } \\
\text { thrombosed and replaced with MVR Silzone. Reoperation at } 7.5 \text { mo for major MVR PPL, re-replacement. }\end{array}$ \\
\hline MR (MVR) & $5.8 \mathrm{y}$ & $\begin{array}{l}\text { Initially mitral commissurotomy, } 21 \text { y later AVR and MVR mechanical prostheses, then } 11 \text { y later AVR } \\
\text { incidental and MVR for PPL, both replaced with Silzone prostheses. Diagnosed with PPL both prostheses } \\
\text { and hemolytic anemia. Re-replacement with bioprostheses for mild AVR PPL and major MVR PPL. }\end{array}$ \\
\hline
\end{tabular}

$A V R$, Aortic valve replacement; $M R$, multiple replacements; $M V R$, mitral valve replacement; $P P L$, paraprosthetic leak. 
TABLE 3. Summary of location, timing, and details of PPLs

\begin{tabular}{|c|c|c|}
\hline Location & Timing & Details \\
\hline \multicolumn{3}{|c|}{ Major PPL: nonoperative mortality } \\
\hline AVR & $15 \mathrm{mo}$ & $\begin{array}{l}\text { Mild to moderate PPL, } \\
\text { progressed to major by } 14 \text { mo; } \\
\text { following definitive diagnosis } \\
\text { patient died at } 15 \text { mo, under } \\
\text { consideration for reoperation. }\end{array}$ \\
\hline \multicolumn{3}{|c|}{ Early PPL considered non-Silzone-related technical error } \\
\hline MVR & $8 \mathrm{~d}$ & $\begin{array}{l}\text { Two reoperations early within } \\
19 \text { d for major PPL; considered } \\
\text { etiology was technical error. }\end{array}$ \\
\hline
\end{tabular}

$\overline{A V R}$, Aortic valve replacement; $M V R$, mitral valve replacement; $P P L$, paraprosthetic leak.

years revealed a PPL in the area of noncoronary leaflet at the repair reoperation and at 5.7 years to the left of the right coronary ostia of the right coronary leaflet at the second reoperation (Table 2).

The 4 earlier-diagnosed major PPLs ( 3 managed with rereplacement, and 1 nonoperative death) were evident between 5 and 15 months. The timing of occurrence of the 5 later major PPLs is uncertain, as these leaks may have become progressively larger over time. The documentation of all major PPL reoperations was reviewed to determine extenuating circumstances but none were identified including annulus considerations, inclusive of residual calcification.

The freedom at 7 years from each of the valve-related complications is illustrated in Table 4, Figure 2, and Figures E1 to E9. The freedom from major PPL (by definition, reoperation plus nonoperative fatality) at 7 years was $95.2 \% \pm 1.5 \%$ for the overall population (Figure 2), $94.9 \% \pm 2.9 \%$ for AVR, and $97.7 \% \pm 1.3 \%$ for MVR. The 10 major PPLs are detailed, as documented above, in Tables 1, 2, and 3.

There were also a total of 8 minor PPL events $(0.57 \%$ / patient-year) that did not require reoperation and were identified on routine echocardiographic examinations. These minor PPL events were 0.42/patient-year (2 events) for
AVR, 0.13\%/patient-year (1 event) for MVR, and 3.0\%/ patient-year (5 events) for MR.

\section{DISCUSSION}

In 1997 and 1998, St Jude Medical received regulatory approval to impregnate the sewing cuffs of valvular prostheses with permanent metallic silver, named "Silzone" coating, to act as prophylaxis against prosthetic valve endocarditis, both an early and late valve-related complication. Subsequently, all St Jude Medical products were impregnated with metallic silver. In 1998, the AVERT was commenced with the anticipation of randomizing 4400 patients in North America and Europe. ${ }^{3}$ The Data Safety Monitoring Board stopped the trial on January 21, 2000, with 807 patients enrolled, because of an increased incidence of major PPL in the Silzone arm compared with the conventional cuff arm. St Jude Medical voluntarily withdrew Silzone products from the worldwide market.

The affiliated teaching hospitals, Vancouver General Hospital and St Paul's Hospital, of the University of British Columbia, had contributed 90 of the institutions' expected 100 patients to the trial. This institutional review of 253 patients incorporates the 44 Silzone patients randomized in AVERT. This review was conducted to contribute to evidence of any continuing risk of late major PPLs necessitating reoperation and major thromboembolic risk of residual morbidity.

The estimated number of patients still alive is approximately 24,000 worldwide of the original 36,000 . This report also attempted to evaluate current evidence for surveillance of this large patient population.

The 2-year results of AVERT were published by Schaff and the AVERT investigators in 2002. ${ }^{1}$ The summary of the 2002 results are outlined in the introduction of this article and in Table 5. The number of major PPLs requiring explant reoperation remained statistically different at 2 years, although the major thromboembolic rate remained undifferentiated statistically. Prior to the 2002 AVERT report, there

TABLE 4. Summary of actuarial analyses (freedom at 7 years; presentation of analyses in electronic Figures E1-E9)

\begin{tabular}{|c|c|c|c|c|}
\hline Figure & Overall & AVR & MVR & MR \\
\hline E1: valve-related reoperation & $95.1 \pm 1.5$ & $95.0 \pm 2.9$ & $97.6 \pm 1.4$ & $84.2 \pm 7.3$ \\
\hline E2: PPL reoperation & $96.4 \pm 1.4$ & $96.2 \pm 2.7$ & $98.4 \pm 1.1$ & $87.7 \pm 6.7$ \\
\hline E3: PPL reoperation mortality & $99.5 \pm 0.5$ & - & - & - \\
\hline $\begin{array}{l}\text { E4: overall thromboembolism, minor TE, RIND, major TE with/ } \\
\text { without thrombosis + major systemic embolism }\end{array}$ & $\begin{array}{l}\text { With: } 78.2 \pm 3.1 \\
\text { Without: } 78.5 \pm 3.1\end{array}$ & - & - & - \\
\hline $\begin{array}{l}\text { E5: combined RIND and major TE with thrombosis + major } \\
\text { systemic embolism }\end{array}$ & $90.3 \pm 2.2$ & $94.9 \pm 3.0$ & $85.0 \pm 3.7$ & 100 \\
\hline $\begin{array}{l}\text { E6: combined RIND and major TE without thrombosis + major } \\
\text { systemic embolism }\end{array}$ & $90.7 \pm 2.2$ & $94.9 \pm 3.0$ & $85.8 \pm 3.6$ & 100 \\
\hline E7: thrombosis & $99.5 \pm 0.4$ & - & $99.2 \pm 0.8$ & - \\
\hline E8: antithrombotic hemorrhage & $84.8 \pm 2.7$ & $89.1 \pm 3.6$ & $85.6 \pm 3.7$ & $69.1 \pm 10.5$ \\
\hline E9: prosthetic valve endocarditis & $98.3 \pm 0.8$ & $98.7 \pm 1.3$ & $98.5 \pm 1.0$ & $96.0 \pm 3.9$ \\
\hline
\end{tabular}


TABLE 5. Summary of reported late event rates (2002 and 2005) and optimal performance criteria for valve replacement devices of the Food and Drug Administration

\begin{tabular}{|c|c|c|c|c|c|}
\hline & \multicolumn{2}{|c|}{ No Silzone, \%/patient-year $(95 \%$ CI $)$} & \multicolumn{2}{|c|}{ Silzone, \%/patient-year (95\% CI) } & \multirow[b]{2}{*}{ OPC } \\
\hline & 2002 & 2005 & 2002 & 2005 & \\
\hline Major prosthetic valve leak & & & & & $0.6 \% / y$ \\
\hline Aortic & $0.9(0.2-3.0)$ & $0.4(0.1-0.9)$ & $3.5(1.7-6.7)$ & $0.6(0.3-1.2)$ & \\
\hline Mitral & $1.5(0.3-4.9)$ & $0.3(0.1-1.1)$ & $7.0(3.1-13.8)$ & $1.6(0.7-2.9)$ & \\
\hline Any prosthetic valve leak & & & & & $1.2 \% / y$ \\
\hline Aortic & $2.3(0.9-5.1)$ & $0.7(0.3-1.3)$ & $5.3(2.9-9.0)$ & $1.3(0.7-2.1)$ & \\
\hline Mitral & $3.8(1.5-8.4)$ & $1.0(0.4-2.0)$ & $8.0(3.8-15.1)$ & $2.3(1.3-4.0)$ & \\
\hline Thromboembolic events & & & & & $3.0 \% / y$ \\
\hline Aortic & $1.4(0.4-3.7)$ & $1.6(1.0-2.5)$ & $2.6(1.1-5.5)$ & $1.5(0.9-2.4)$ & \\
\hline Mitral & $3.8(1.5-8.4)$ & $2.0(1.1-3.3)$ & $9.0(4.5-16.5)$ & $5.5(3.7-7.8)$ & \\
\hline RIND & & & & & $0.8 \% / y$ \\
\hline Aortic & $0.0(0.0-1.2)$ & - & $0.4(0.1-2.1)$ & - & \\
\hline Mitral & $0.0(0.0-1.9)$ & - & $2.0(0.4-6.4)$ & - & \\
\hline Stroke & & & & & $0.8 \% / y$ \\
\hline Aortic & $0.0(0.0-1.2)$ & $0.1(0.0-0.4)$ & $0.4(0.1-2.1)$ & $0.4(0.1-0.9)$ & \\
\hline Mitral & $0.8(0.1-3.6)$ & $0.7(0.2-1.6)$ & $3.0(0.9-8.0)$ & $1.8(0.9-3.2)$ & \\
\hline Valve thrombosis & & & & & $0.8 \% / y$ \\
\hline Aortic & $0.0(0.0-1.2)$ & $0.0(0.0-0.2)$ & $0.0(0.0-1.1)$ & $0.1(0.0-0.4)$ & \\
\hline Mitral & $0.0(0.0-1.9)$ & $0.0(0.0-0.4)$ & $1.0(0.1-4.7)$ & $0.4(0.1-1.3)$ & \\
\hline Bleeding event & & & & & $3.5 \% / y$ \\
\hline Aortic & $1.4(0.4-3.7)$ & $1.6(1.0-2.5)$ & $3.5(1.7-6.7)$ & $2.1(1.4-3.1)$ & \\
\hline Mitral & $0.8(0.1-3.6)$ & $3.0(1.8-4.6)$ & $6.0(2.5-12.4)$ & $2.9(1.7-4.7)$ & \\
\hline
\end{tabular}

was limited documentation on the experience of the St Jude Medical Silzone prostheses with no concern for excessive valve-related complications. ${ }^{4-6}$ These investigators did not participate in the AVERT trial and found their results superior to the AVERT results with no identified PPLs.

In 2003, Ionescu and coinvestigators ${ }^{7}$ reported on the $\mathrm{St}$ Jude Medical Silzone prosthesis experience from the Cardiff Embolic Risk Factor Study. This significant report came from a prospective observational study of risk factors for stroke after valve replacement. These authors compared the results of 51 patients with Silzone prostheses with 116 patients with St Jude Medical standard prostheses matched for stroke risk factors. The authors reported comparable results with AVR, but with MVR, freedom from major thromboembolism was $65 \%$ for Silzone prostheses and $95 \%$ for standard prostheses at 3 years. Patients in the Silzone group experienced 6 major strokes and 1 peripheral embolus within 3 months. There was 1 reoperation for major PPL in the standard group but none in the Silzone group.

Stalenhoef and coauthors ${ }^{8}$ reported in 2003 on an experience with 113 patients receiving Silzone and 101 conventional prostheses in a consecutive series. They identified very favorable results with no difference in either thromboembolism or paraprosthetic leakage. The authors speculate that the good results were due to differences in operative techniques.

The mechanism of defective healing of the sewing cuff to the annular tissues is not completely understood. It has been postulated that the Silzone coating inhibits normal fibroblast growth into the prosthesis sewing cuff. ${ }^{7}$ The inhibited healing results in sporadic prosthetic dehiscence with partial and intermittent lack of tissue ingrowth and endothelization. ${ }^{7}$ The resultant toxic tissue necrosis can result in thrombus accumulation and loosening of sutures and paraprosthetic leakage. $^{7}$ The annular necrosis can give the suggestion of findings compatible with prosthetic valve endocarditis, but the material is usually culture negative.

The mechanism may be influential in the alteration of healing. Ionescu and collaborators ${ }^{7}$ felt that pledgeted mattress sutures could cause pressure necrosis from lightened sutures. There is actually evidence to the contrary. Englberger and colleagues ${ }^{9}$ reported for the AVERT study that suture technique without pledgets was an independent risk factor for major PPLs. The rate of leaks with pledgets was $1.7 \%$ and $5.8 \%$ without. The hazard ratio was 0.3 and 2.5 , respectively. There was no association with valve position.

The important question of whether the incidence of late $(>30$ days) valve-related complications rates persists with time is addressed in the summary of the AVERT results presented in 2002 and 2005 (Table 5). The 2002 rates of thromboembolism and stroke failed to be differentiated statistically. ${ }^{1}$ In a further unpublished AVERT analysis in 2005, the stroke rate for AVR was $0.1 \%$ patient-year for no Silzone and $0.4 \%$ for Silzone. ${ }^{10}$ The rates for MVR were $0.7 \%$ /patient-year and $1.8 \%$ /patient-year, respectively. ${ }^{10}$ The freedom from thromboembolism during the first 5 years was not different $(P=.54){ }^{10}$ 
The 2002 rates of major PPL were: AVR, 0.9\%/patientyear for no Silzone and 3.5\%/patient-year for Silzone; MVR, $1.5 \%$ /patient-year and 7.0\%/patient-year, respectively. ${ }^{1}$ In 2005, the major PPL rates were: $0.4 \%$ /patient-year for no Silzone and $0.6 \% /$ patient-year for Silzone for AVR and $0.3 \% /$ patient-year and 1.6\%/patient-year for MVR, respectively. ${ }^{10}$ Major PPLs occurred in 17 patients with Silzone and 6 patients with no Silzone. ${ }^{10}$ The freedom from major PPLs for AVR was not different $(P=.42)$ but for MVR was different $(P=.03) .{ }^{10}$ The overall reoperation for prostheses explant at 5 years remained different $(P=.001){ }^{10}$ Beyond the 2-year postoperative interval, both the Silzone and conventional non-Silzone arms were identified as having 3 major PPLs each. ${ }^{10}$ In the current study, the overall freedom from major PPL for AVR, at 7 years, was $94.9 \%$ and for MVR, $97.7 \%$. These freedoms were better for MVR but slightly worse for AVR compared with the AVERT rates.

The concept of Objective Performance Criteria (OPC) was adopted in 1994 by the Food and Drug Administration of the United States for utilization of approval of valvular prostheses. ${ }^{11}$ The $95 \%$ confidence interval $(\times 2)$ of the linearized occurrence rate ( $\%$ per patient-year) of any valve-related complication must be less than double the respective OPC. The OPCs were determined by meta-analysis for evaluation for performance of aortic and mitral prostheses but not multiple replacements. ${ }^{12}$ The OPCs are stated in Table 5 with the 2002 and 2005 AVERT rates. In this study, the calculated linearized occurrence rates for major PPL, major thromboembolism (stroke + reversible ischemic neurologic deficits), and hemorrhage were all within acceptable levels except major PPL for AVR $(95 \%$ linearized occurrence rates $1.34>0.6 \mathrm{OPC} \times 2=1.2$ ).

In 2006 , Grunkemeier and colleagues ${ }^{13}$ studied the risk of PPL beyond 5 years to afford advice to the remaining 28,000 patients estimated to be alive with the Silzone prosthesis. These authors reported the major PPL rate within 2 years was $1.9 \% /$ patient-year $^{14}$ for Silzone and $0.4 \% /$ patient-year ${ }^{3}$ for non-Silzone, and event rates beyond 2 years to 5 years was similar: $0.3 \%$ patient-year in both arms, 3 patients in each arm. ${ }^{13}$ In the current study, the linearized occurrence rates for major PPL was 1.3\%/patient-year within 2 years and late after 2 years, $0.4 \%$ /patient-year. Davila-Roman and colleagues ${ }^{14}$ evaluated all the echocardiograms in both arms and reported in 2004. They excluded the early major PPLs and found no difference in prevalence or severity of PPLs after 2 years. The identified physiologic regurgitation was found to be hemodynamically not significant.

There is currently adequate evidence to identify the risk of major PPL and thromboembolism in the patients who remain alive with a Silzone prosthesis. ${ }^{13,14}$ Horstkotte and Bergemann ${ }^{15}$ concluded that overall thromboembolic and hemorrhagic complications are similar for Silzone cuffs and conventional cuffs and that the standard antithrombotic regimes need not be changed. The major PPL rate is now similar in the Silzone and conventional cuff arms of AVERT and in the current 7-year study. ${ }^{13,14}$

The American College of Cardiology/American Heart Association practice guidelines recommend that asymptomatic, uncomplicated patients need only be seen at 1-year intervals for complete history and thorough physical examination. ${ }^{16}$ The follow-up of patients with complications or potential complications who have had prosthetic heart valve replacement and do not improve after surgery or later show deterioration of functional classification should include appropriate testing, including 2-dimensional and Doppler echocardiography, and, if necessary, transesophageal echocardiography and cardiac catheterization with angiography to determine the cause. ${ }^{16}$ The Canadian Cardiovascular Consensus on Surgical Management of Valvular Heart Disease recommends that Doppler echocardiography should be performed between 5 and 30 days after operation and again between 6 and 12 months after surgery, after which there is no firm recommendation except that a study should be performed at the slightest suspicion of dysfunction. ${ }^{17}$ Dysfunction may be suspected by a reduction in one functional class from the maximal recovery New York Heart Association functional class. ${ }^{17}$ The recommended follow-up interval for echocardiography can be based on the type of prosthesis and the documented knowledge of potential dysfunction. ${ }^{17}$ The follow-up for heterograft bioprostheses is echocardiography at discharge, 30 days, 6 to 12 months, 5 years, and annually after 7 years for MVR and after 10 years for AVR or any clinical suspicion of dysfunction. For mechanical prostheses, echocardiography should be performed at discharge, 30 days, and 6 to 12 months or any clinical suspicion of dysfunction. ${ }^{17}$ The surveillance of patients with the Silzone prosthesis can now meet recommended standards established for care of patients with mechanical prostheses. There is no advanced continuing risk of valve-related complications with the St Jude Medical Silzone prosthesis after 2 years following implantation.

We extend appreciation to Kevin Shillitto for his work in the preparation of the manuscript.

\section{References}

1. Schaff HV, Carrel TP, Jamieson WRE, Jones KW, Rufilanchas JJ, Cooley DA, et al. Para-prosthetic leak and other events in Silzone-coated mechanical heart valves: a report from AVERT. Ann Thorac Surg. 2002;73:785-92.

2. Edmunds LH Jr, Clark RE, Cohn LH, Grunkemeier GL, Miller DC, Weisel RD. Guidelines for reporting morbidity and mortality after cardiac valvular operations. The American Association for Thoracic Surgery, ad hoc liaison committee for standardizing definitions of prosthetic heart valve morbidity. Ann Thorac Surg. 1996;62:932-5.

3. Schaff H, Carrel T, Steckelberg JM, Grunkemeier GL, Holubkov R. Artificial valve endocarditis reduction trial (AVERT): protocol of a multicenter randomized trial. J Heart Valve Dis. 1999;8:131-9.

4. Kjaergard HK, Tingleff J, Abildgaard U, Pettersson G. Recurrent endocarditis in silver-coated heart valve prosthesis. J Heart Valve Dis. 1999;8:140-2. 
5. Auer J, Berent R, Ng CK, Punzengruber C, Mayr H, Lassnig E, et al. Early investigation of silver-coated Silzone heart valves prosthesis in 126 patients. $J$ Heart Valve Dis. 2001;10:717-23.

6. Herijgers P, Herregods MC, Vandeplas A, Meyns B, Flameng W. Silzone coating and para-prosthetic leak: an independent, randomized study. J Heart Valve Dis. 2001;10:712-5; discussion 715-6.

7. Ionescu A, Payne N, Fraser AG, Giddings J, Grunkemeier GL, Butchart EG. Incidence of embolism and paravalvar leak after St Jude Silzone valve implantation: Experience from the Cardiff embolic risk factor study. Heart. 2003;89:1055-61.

8. Stalenhoef JE, Mellema EC, Veeger NJ, Ebels T. Thrombogenicity and reoperation of the St. Jude Medical Silzone valve: a comparison with the conventional St. Jude Medical valve. J Heart Valve Dis. 2003;12:635-9.

9. Englberger L, Schaff HV, Jamieson WRE, Kennard ED, Im KA, Holubkov R, et al. Importance of implant technique on risk of major para-prosthetic leak (PVL) after St. Jude mechanical heart valve replacement: a report from the artificial valve endocarditis reduction trial (AVERT). Eur J Cardiothorac Surg. 2005;28:838-43.

10. Schaff HV, Carrel TP, Jamieson WRE, Jones KW, Rufilanchas JJ, Cooley DA, et al. Para-prosthetic leak and other events in Silzone-coated mechanical heart valves: a report from AVERT. AVERT Investigators Report. University of Pittsburgh Coordinating Center; Pittsburgh. 2005.
11. FDA Replacement Heart Valves Draft Guidance, Version 4.1. Washington, D.C. U.S. Department of Health and Human Services. 1994.

12. Grunkemeier GL, Johnson DM, Naftel DC. Sample size requirements for evaluating heart valves with constant risk events. J Heart Valve Dis. 1994;3:53-8.

13. Grunkemeier GL, Jin R, Im K, Holubkov R, Kennard ED, Schaff HV. Timerelated risk of the St. Jude Silzone heart valve. Eur J Cardiothorac Surg. 2006; 30:20-7.

14. Davila-Roman VG, Waggoner AD, Kennard ED, Holubkov R, Jamieson WRE, Englberger L, et al. Prevalence and severity of para-prosthetic regurgitation in the artificial valve endocarditis reduction trial (AVERT) echocardiography study. J Am Coll Cardiol. 2004;44:1467-72.

15. Horstkotte D, Bergemann R. Thrombogenicity of the St. Jude Medical prosthesis with and without Silzone-coated sewing cuffs. Ann Thorac Surg. 2001;71:1065.

16. Bonow RO, Carabello BA, Chatterjee K, de Leon AC Jr, Faxon DP, Freed MD, et al. ACC/AHA 2006 guidelines for the management of patients with valvular heart disease: a report of the American College of Cardiology/American Heart Association Task Force on Practice Guidelines. J Am Coll Cardiol. 2006;48:e1-148.

17. Jamieson WRE, Cartier PC, Allard M, Boutin C, Burwash IG, Butany J, et al. Surgical management of valvular heart disease 2004. Can J Cardiol. 2004 20(suppl E):7E-120E. 


\section{ADDENDUM}

Since the closing interval in November 2005 and statistical analysis in 2006, there has been an additional late paraprosthetic leak that led to reoperation at 71 months (5 years, 11 months) following implantation of a Silzone aortic pros-

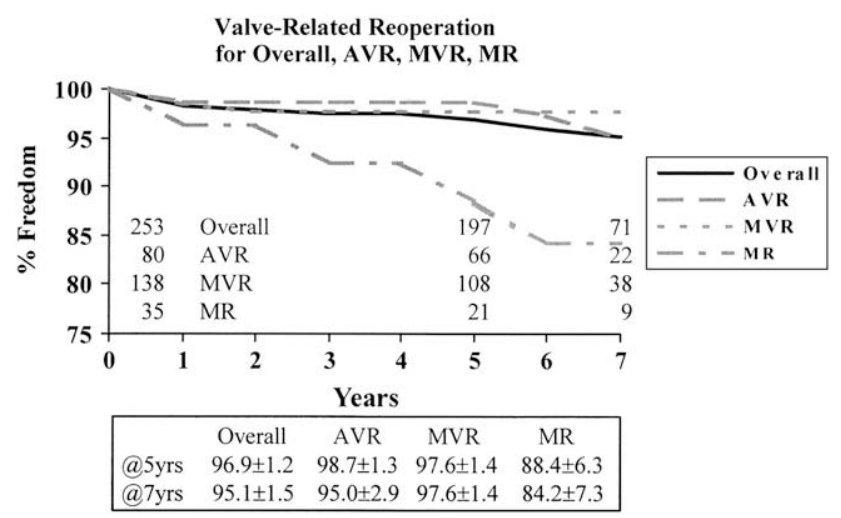

FIGURE E1. Valve-related reoperation overall and for aortic valve replacement $(A V R)$, mitral valve replacement $(M V R)$, and multiple replacements $(M R)$. thesis. At reoperation, 2 large paraprosthetic leaks were identified, and further annular decalcification was necessary. There was no fibrous overgrowth, thrombus, or vegetations. A small amount of "rubbery" grayish-white to tan-brown material was identified that was nondiagnostic.

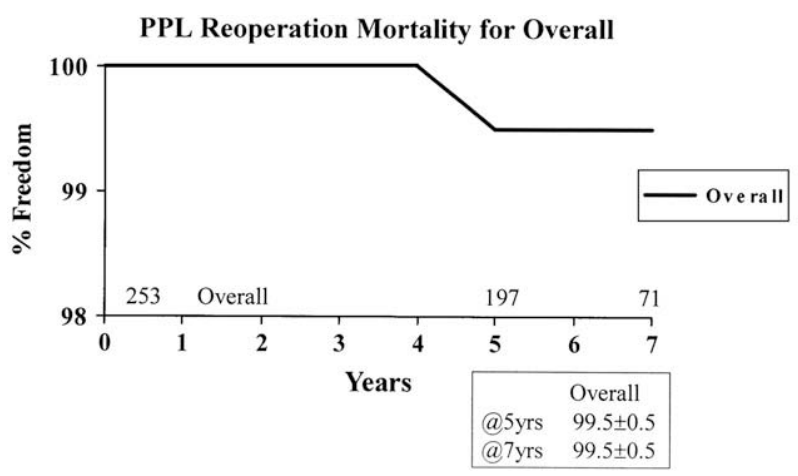

FIGURE E3. Paraprosthetic leak reoperation mortality overall.

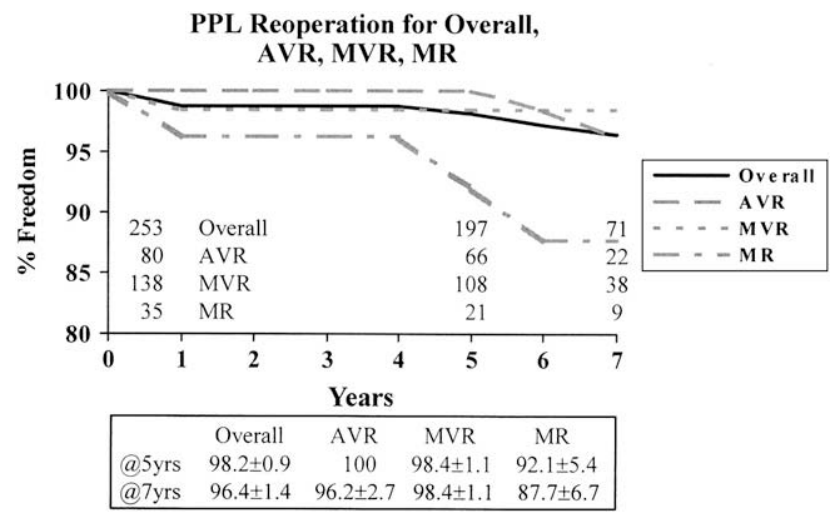

FIGURE E2. Paraprosthetic leak reoperation overall and for aortic valve replacement $(A V R)$, mitral valve replacement $(M V R)$, and multiple replacements $(M R)$.
Overall Thromboembolism, Minor TE, RIND, Major TE with/without Thrombosis plus Major Systemic Embolism Overall

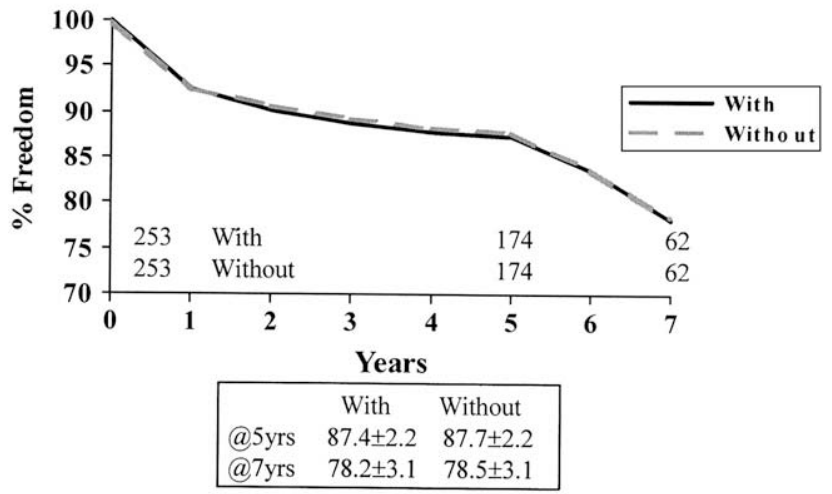

FIGURE E4. Overall thromboembolism, minor thromboembolism (TE), reversible ischemic neurologic deficits, major TE with/without thrombosis plus major systemic embolism (overall). 
Combined RIND and Major TE

with Thrombosis plus Major Systemic Embolism for Overall, AVR, MVR, MR

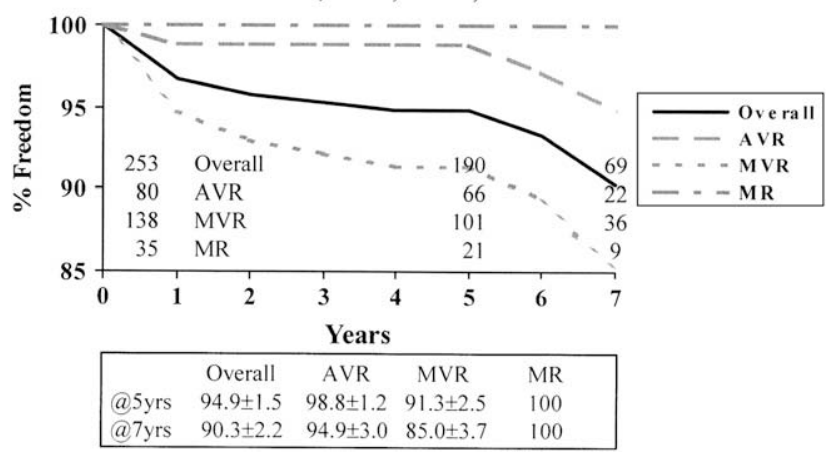

FIGURE E5. Combined reversible ischemic neurologic deficit (RIND) and major thromboembolism (major TE) with thrombosis plus major systemic embolism overall and for aortic valve replacement $(A V R)$, mitral valve replacement $(M V R)$, and multiple replacements $(M R)$.
Combined RIND and Major TE

without Thrombosis plus Major Systemic Embolism for Overall, AVR, MVR, MR

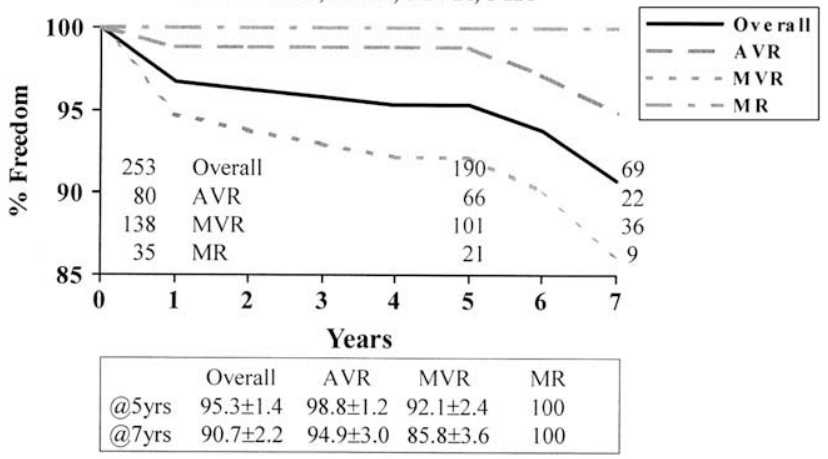

FIGURE E6. Combined reversible ischemic neurologic deficit (RIND) and major thromboembolism (major TE) without thrombosis plus major systemic embolism overall and for aortic valve replacement (AVR), mitral valve replacement $(M V R)$, and multiple replacements $(M R)$.

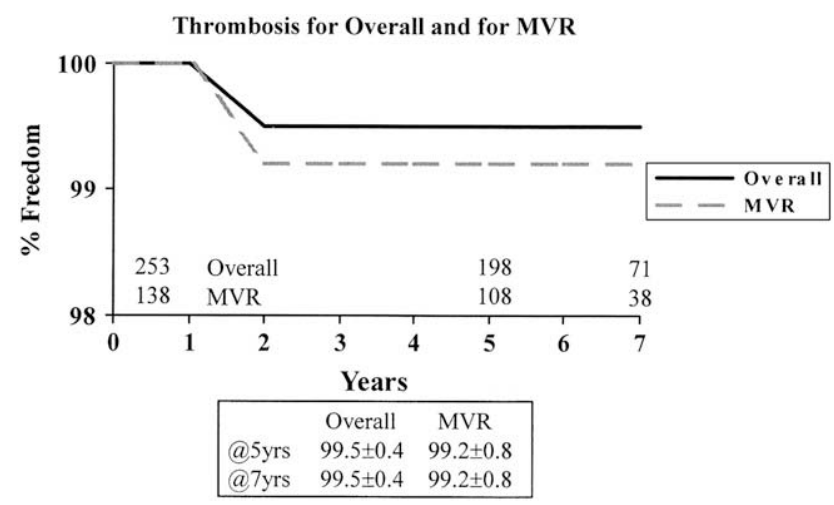

FIGURE E7. Thrombosis overall and for mitral valve replacement (MVR)

Antithrombotic Hemorrhage (ATH) for Overall, AVR, MVR, MR

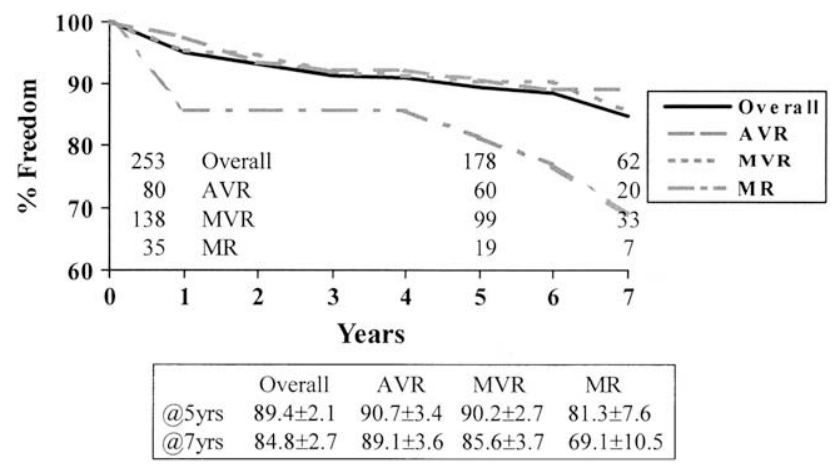

FIGURE E8. Antithrombotic hemorrhage overall and for aortic valve replacement $(A V R)$, mitral valve replacement $(M V R)$, and multiple replacements $(M R)$.

Prosthetic Valve Endocarditis (PVE) for Overall, AVR, MVR, MR

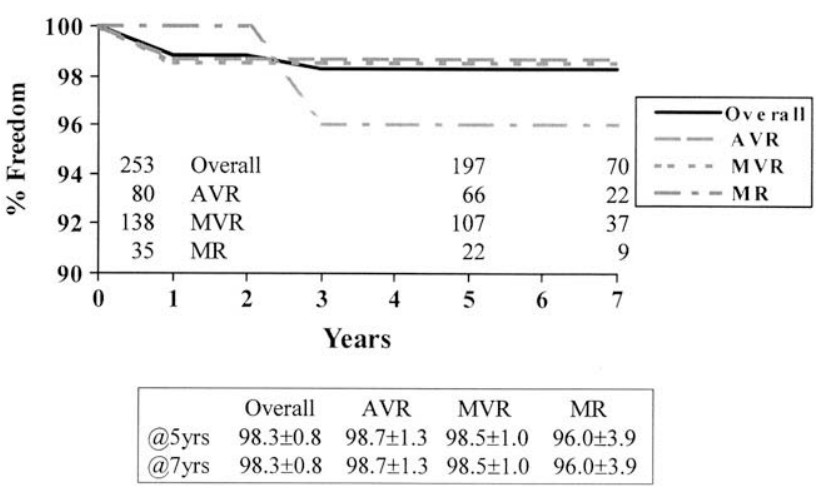

FIGURE E9. Prosthetic valve endocarditis overall and for aortic valve replacement $(A V R)$, mitral valve replacement $(M V R)$, and multiple replacements $(M R)$. 